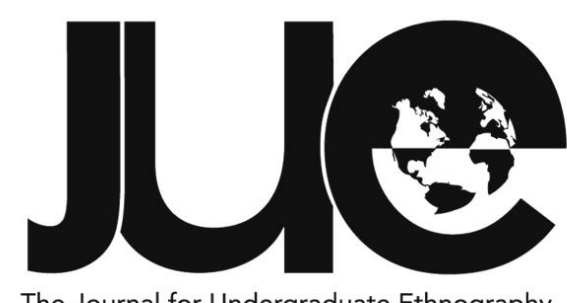

\title{
Upscaling Downtown: Interpersonal Dynamics of Nightlife Revelers in Geneva, New York
}

\section{Chloé Sudduth}

Hobart and William Smith Colleges_chloemsudduth@gmail.com

\section{ABSTRACT}

Bars have long been recognized as the intersection of a city's culture and commerce. They provide opportunities for social interaction, contain a multitude of local memories, and serve as sources of identity. The American Revolution, the Whiskey Rebellion, and the Stonewall riots all developed out of local bars. So, what does it mean when the character of bars in a neighborhood begins to change? How do these changes to commercial spaces affect the social fabric of a city? Using a combination of ethnographic fieldwork and interviews, I explore the upscaling of the downtown bar scene in Geneva, New York to unpack what these commercial changes mean for the disparate groups that frequent the downtown space. I argue that instead of simply diversifying the types of businesses available to consumers in Geneva, this development has altered the very character and social fabric of downtown. Rather than creating an integrated and cohesive nightlife scene in which disparate groups come together in shared space and time, this development manifests in the fragmentation of the downtown scene in new ways that increase the segregation of people in social space.

Keywords: urban sociology; bars; commercial upscaling; ethnography; integrated segregation 
$\mathrm{t}$ is about $11 \mathrm{pm}$ on a cold Friday night in January. Two well-dressed couples in their twenties walk into The Point - one of the newest upscale bars in Geneva, a small city in the Finger Lakes region of upstate New York. As the couples approach the bar, they point and whisper in awe of the sophisticated interior décor. The women are wearing classy dresses and chic wool coats with their hair neatly falling just below their shoulders. The men are wearing dress pants, button up shirts with sweaters and hip trench coats. Pete, the head bartender of this cocktail bar, is wearing the 'uniform' of dress pants, a button up shirt with a vest and tie. The group proceeds to ask Pete about a few drinks on the menu, looking for a more detailed explanation of the hand-crafted cocktails. They each order a different cocktail so that they can try as many as possible. The two couples dance, chat among themselves and take pictures of Pete making their drinks. When their drinks arrive, one of the women mentions that her drink features a lime peel setting atop the ice illuminated by a blue flame. The couples take a few moments to taste each other's drinks before proceeding to take selfies with their elaborate cocktails. The four continue their night sitting at the leather tufted nailhead couches and glass tables beyond the bar in a dimly lit corner with a more personal and private feel.

The above interaction was not one in a bar in New York City or Los Angeles, but in a new bar in the small city of Geneva in the Finger Lakes region of New York. Ten years ago, this interaction would not have been representative of any nightlife experience in Geneva, but between 2013 and 2017, seven new upscale bars and restaurants have moved into downtown Geneva, New York - a city of under 13,000. Geneva's downtown was once characterized by casual, local watering holes but now includes a microbrewery, a wine bar, a farm-to-table restaurant, and a prohibition-style cocktail bar among its new attractions for nightlife revelers. I became interested in how these commercial shifts would impact such a small city. If seven or eight new businesses move into a city that is just over 4.3 square miles, changes may be more palpable than they would be in a larger-scale city. In this paper, I explore these commercial changes through an analysis of interpersonal dynamics within and between various commercial spaces in Geneva.

\section{Bars as the Intersection of City Culture and Commerce}

While public space, by definition, tends to be viewed as open and accessible to a variety of people, the reality of such openness is contested in the literature. According to sociologist Lyn Lofland, social constraints exist that specify who can occupy particular public spaces even though the spaces are visually and physically accessible (Lofland 1998, 8). These constraints tend to center upon normative expectations regarding markers such as class, race, and gender, applied to physical locations in space. As the French philosopher Henri Lefebvre notes, these are typically the ideologies of the dominant class, given their position to control the space (Lefebvre 1991). The social meanings given to public space by those in the dominant class are not to be taken as merely repressive and exclusionary. Individuals and groups who are excluded from certain spaces often contest both the purpose and use of that space, creating conflict.

Bars serve as a fascinating intersection of a city's culture and commerce, as well as its public and private space. Numerous studies have analyzed bars as important spaces for sociability, community, and sense of place (Grazian 2003; Grazian 2008; May 2014; Lloyd 2006; Oldenburg 1989). These works focus on the role that bars play in people's lives - as sites for cultural experiences, identity performance, or sources of community - and almost exclusively focus on larger cities (Grazian 2003; Grazian 2008; May 2014; Lloyd 2006; Oldenburg 1989). These studies offer vital groundwork for understanding the importance of bars across 
various sites and moments in time as well as the performative social dynamics that occur within and between them. They also illuminate the changing boundaries of public and private space and what it means to have a right to one's city (Zukin 2008, 2010, 2011; Zukin et al. 2009). Intrigued by the rapid rate of commercial change I was seeing, I wanted to understand how these commercial changes were impacting the social dynamics in downtown Geneva.

The intersections of a city's culture and commerce are best understood by analyzing the interpersonal dynamics of the social spaces themselves. Reuben May (2014) explores how nightlife revelers navigate downtown space as they go about meeting, socializing, and entertaining themselves. May's work begins with a spatial analysis of the nightlife scene of a popular city in Georgia, in which he defines people in "caravanning groups" that operate in "social capsules" formed by symbolic boundaries (May, 2014, 13-14). These groups that move in social capsules enforce boundaries against excluded groups (May, 2014, 15). May's work reveals the ways that disparate groups see public space and the conflicts that arise in the streets, in bars and nightclubs, and in various public spaces throughout the downtown space.

May's study provides rich material from which to approach an analysis of the social dynamics at play in and between these new commercial spaces in Geneva. May develops the concept of "integrated segregation" - the idea that diverse groups are physically close to one another yet rarely have meaningful interactions, but rather are socially bound to those of similar race, class, and cultural backgrounds. Throughout the text, May argues that social tension between groups is persistent because many participants fail to make the connection between their current relations with other groups and the historical and institutional forces that perpetuate those very tensions. The thinly veiled structural racism in the downtown entertainment space is revealed, illustrating the direct influence of local government and nightlife management decision-making on interpersonal interactions among groups. In studying social dynamics of nightlife in Geneva, I employ a similar spatial analysis in an attempt to understand how nightlife revelers utilize and move through the downtown nightlife scene.

\section{Taste and Exclusivity in Commercial Change}

Sociologist Richard Ocejo (2014) analyzes the influence of government and nightlife management on the downtown scene in a neighborhood in New York City, exploring a once working-class area that now features luxury housing, chic boutiques, and a vibrant nightlife culture. His work investigates how various groups are affected by this urban transformation, arguing that the gentrifying neighborhoods of many post-industrial cities are influenced by commercial upscaling. Ocejo utilizes the actions and perspectives of residents, visitors, public officials, and nightlife actors to explore the contested and dynamic process of neighborhood change, finding that New York City's growth agenda has produced a commercial scene that appeals to and benefits wealthy and transient people and prioritizes their interests over those of existing residents (Ocejo 2014, 212).

Ocejo's work centers the impact of commercial change on everyday life in today's post-industrial cities. Recognizing that bars rest at the intersection of a city's culture and its economy, Ocejo utilizes bars as a window through which to view the changes in local social patterns, the formation of local identities, and the transformation of neighborhoods. This framing of bars as a tool to understand social dynamics became vital in my work in Geneva. Ocejo shows that the exclusivity of nightlife scenes may not be new, but the upscale nature of the cultures, tastes, and consumers that compose the scenes are. This notion of nightlife scenes shifting towards more upscale cultures and tastes is representative of the shifts in consumption scenes in Geneva. This contemporary form of downtown neighborhood exclusivity is driven by cities' growth agendas that appeal to and benefit wealthy newcomers and visitors - prioritizing their tastes and needs over those of existing residents (Zukin 2008, 2011). Wealthy and transient groups flock to these neighborhoods and use these new spaces to create and reinforce imagined communities based on 
forms of commercial leisure, taste, and desire at the expense of people in actual place-based communities (Ocejo 2014, 210). The social context of Geneva combines local residents, college students, and tourists - all interacting in downtown space. Each group comes to the nightlife scene with different identities, tastes, and intentions. The question of whose tastes are catered to is wrapped up in cities' agendas and the relationship between culture and commerce.

\section{Race, Commodification, and Authenticity}

Another study looking at the intersection of a city's culture and its commerce is David Grazian's (2003) book studying the world of contemporary blues clubs in Chicago, which reveals how curated images of the blues are manufactured and sold to blues audiences. Grazian argues that the desire to experience authenticity in the postmodern world propels the popularity of the blues (Grazian 2003, 9). Drawing on countless hours spent in blues clubs throughout Chicago, Grazian shows how this quest for authenticity has transformed blues itself with professional and amateur musicians, club owners, and city boosters defining, packaging, and dishing the blues out to tourists and bar patrons. Rather than defining an authentic blues experience, Grazian seeks to explain how the commodification of the blues drives producers and consumers to a certain perception of authenticity. Similar performative dynamics are at play in various bars in Geneva in the manufacturing of a nightlife experience characterized by specialty cocktails and farm-to-table restaurants.

Tourism - a supposed economic solution to the declining manufacturing industrial economy - becomes a main motivation for the city of Chicago to promote the blues and its legacy in the city (Grazian, 2003). Through this perceived authenticity of the blues, race - and the performance of race - becomes vital to the packaging of the "authenticity" of the Chicago blues scene. Grazian shows us how, for consumers, blackness came to connote a sense of authenticity of the blues. Thinly veiled relationships between place and authenticity also define the good nightlife experience for revelers in Geneva.

Bars have always been situated at the intersection of a city's culture and commerce and they serve as rich sites for understanding neighborhood change. I sought to explore the social dynamics that govern these nightlife spaces in Geneva to understand whether these commercial shifts were bringing changes in interactions and use patterns. Who were these spaces for and who was disinvited from them? What did the upscaling of downtown mean for the people living in Geneva relative to transient groups like students and tourists? Were there changes in use patterns and social interaction in the downtown space? My study provided an opportunity to build on the work of people like Reuben May and Richard Ocejo by providing an intimate look at what happens to the very social fabric of a community amidst these economic shifts and the contested interactional dynamics of these changing spaces.

\section{Research Methods}

To capture these changes and understand the mechanisms through which they operate, I decided to utilize a combination of ethnographic fieldwork and interviews similar to Ocejo's methods (2003). The ethnographic fieldwork provided an opportunity to observe how people interacted in each of the bars and compare the nature of interactions between bars in the downtown space. Through my ethnography, I was able to see patterns across time and space in downtown Geneva that helped me to make sense of how the downtown nightlife is structured. This ethnographic work allowed me to observe the mechanisms through which these patterns create and recreate integrated segregation. Over four months, I conducted ethnographic fieldwork in three bars in downtown Geneva. I chose to focus on a local bar, a college bar, and an upscale bar to compare the perceived groups in the downtown nightlife space. In addition to several hours of informal acclimation to the downtown nightlife scene, I spent a total of eleven hours of formal research in the upscale bar (The Point), ten hours in the college bar (Ray's Place), and ten hours in the local bar (Mertin's bar). I focused my fieldwork 
on Thursday, Friday, and Saturday evenings, because these popular nightlife days and times were the times when interactions that I wanted to study would occur. While in these spaces, I took extensive fieldnotes of the atmosphere of the bar, the patrons in the bar and the nature of interactions amongst patrons and bartenders. I also noted interactions between myself and the bartenders or myself and patrons as I navigated my role as a researcher. During my time in these spaces, I conducted many conversations and informal interviews with bar owners, workers, and patrons. I wrote these conversations down quickly in my research notebook after the interaction ended.

In addition to the ethnographic fieldwork, I wanted to gain an understanding of the ways in which nightlife workers interpret and assign meaning to the social world in which they work. I decided to conduct formal interviews with bar owners and workers and (on one occasion) a patron. This allowed me to ask more direct questions and explore the views, experiences, beliefs, and perspectives of the nightlife workers in Geneva. Over the course of my research, I conducted seven formal interviews. In the upscale bar, I interviewed one middleaged, white, male owner and two white, male bartenders in their twenties. In the college bar, I interviewed one middle-aged, white, male owner and one white, male bartender in his thirties. In the local bar, I interviewed one black, female bartender in her thirties and one black, male patron in his sixties. These interviews allowed me to understand how workers perceive their role as actors of the nightlife consumption scene and how they operate to support or challenge the social dynamics at play.

\section{Understanding Bar Wisdom}

The patterns that I began to observe formed a body of knowledge that seemed to guide groups in Geneva through interactions in different bars. Similar dynamics were also visible in the ways in which disparate groups interacted within each bar. Knowledge of these informal rules operates to allow individuals and groups to develop what I call bar wisdom. In developing the concept of becoming barwise, I was inspired by Elijah Anderson's (1990) concept of 'streetwise', developed in his urban sociological study of race, class, and change:

This street wisdom is largely a state of mind, but it is demonstrated through a person's comportment. It represents a perspective gained through public interaction, the give and take of street life. This perspective allows one to 'see through' public situations, to anticipate what is about to happen based on cues and signals from those encounters. In essence, a 'streetwise' person is one who understands 'how to behave' in uncertain public places. (Anderson 1990, 5-6)

While Anderson's concept of streetwise refers to the wisdom governing interactions on the street, my use of barwise refers to knowledge and understanding of social rules that govern interaction in bars and illuminates differences in interactions between various bars. The rules of bar wisdom, much like street wisdom, are largely structured by race, class, and gender. This knowledge is applied at two levels: how patrons decide which bars to visit and how they interact in them. In this paper, I highlight the décor/atmosphere of the bar, clothing or style of dress among patrons, and notions of who is to be where, when, as mechanisms through which patrons deploy bar wisdom. This understanding often informs what spaces they choose to frequent at what time as well as the ways they interact or do not interact with other groups in the space. Despite the fact that these upscale bars bring a new clientele downtown, they nonetheless result in a segregated scene shared by different groups that do not interact significantly and/or get along.

\section{Décor and Atmosphere of the Bars}

The upscale bar, The Point, is located towards the end of a dimly lit street with drapes over the windows and a small, neon sign beckoning you to enter. It looks dark inside. Upon opening the door, you see the large wrap around bar, dimly lit grunge-chic exposed brick on the walls, and tin ceiling tiles. The right-hand wall holds the bar, which is lined with liquor bottles neatly displayed in front of mirrors with backlighting. The barstools feature a wooden seat with a copper metal frame that enhances the grungechic appeal. On the right-hand side of the bar, leather and velvet tufted nailhead couches offer a more intimate and personal space for 
gathering. Black leather couches line the corners creating an alcove on either side of the bar and include small, round glass tables for cocktails to be displayed as folks sit and converse with one another. The walls are decorated with a variety of mirrors and framed pictures for sale as well as a large white caribou head.

The contrast of materials and textures such as exposed brick, black painted walls, wood, leather, velvet, and metal create a posh, industrial-chic feel that is unique to the newer businesses in Geneva. The space feels romantic; it reminds one of both an upscale, urban experience, but also a nostalgic trip back to Prohibition times. The bartenders wear dress pants, button-up shirts, vests, and ties. Their hair is neat, and they maintain a traditionally professional demeanor at the bar, such as greeting people upon arrival, communicating in formal English, maintaining a certain social distance, and wishing them a safe night as they leave. The music varies from 80 s classics to smooth jazz depending on the night and the crowd. Patrons sit at the bar or congregate in groups within small, benched alcoves. When the bar is more crowded, groups may stand behind the bar along the tall tables on the lefthand side of the space.

Around the corner from The Point, Ray's Place is situated along a row of businesses in a main strip of downtown Geneva. The windows facing the street feature foggy, opaque glass aiding the unassuming exterior with a few staple neon beer signs in the windows. A few bouncers typically sit outside smoking or drinking beer. Inside the bar, you encounter loud music playing and a forty-six-foot wooden bar. The bartenders are mostly male and dressed casually in flannel shirts and blue jeans. Female bartenders tend to dress in blue jeans and a nice top. The space has tall, cathedral ceilings with wood covering most of the interior. Exposed brick covers one side wall with black drop ceiling panels and wood floors. The bar itself is long and narrow, extending far beyond what is clearly visible upon entrance. There is a small, raised, wooden stage and an open space that often serves as a dance floor. The forty-six-foot bar is to the right, just beyond the dance floor and to the left are tall bar stools extending along the same length as the bar. The space includes a few arcade games, a dartboard, and two pool tables as you walk further towards the back. At the very back of the bar, there are usually no lights on and just a few mismatched couches and chairs that often hold piles of patrons' coats.

On a nearby street, Mertin's bar is situated next to an upscale tavern and a vacant storefront. Its brick exterior with neon beer signs in the windows characterizes the space as a traditional local bar. This bar is frequented almost exclusively by local working-class residents. Most of the patrons are middle-aged or older. This bar's patronage has a fairly diverse racial makeup and typically more men than women. A few people are almost always hanging just outside the door smoking a cigarette. They often meet you with a smile, a hello, and a casual comment about the weather or just a simple "How are you?" This is often a point referenced by local patrons who boast of the "authenticity" of this bar as compared to other bars downtown.

The bar appears to have been two separate storefronts at one point eventually having the center wall knocked out to join the rooms into one. Even with this, the space feels small. The ceilings are low and the space is narrow. Along the right-hand side wall is an old wooden bar. Straight ahead is a walkway leading back to the bathrooms in the back of the bar. To your left is an open space that feels quite empty most of the time with the exception of a game of pool being played occasionally. Typical of local bars, the décor looks somewhat rundown with most of the bar stools crooked, broken, or breaking and the bar, cabinetry and glasses a mismatched combination. Most of the interior wall space of the bar is covered in beer signs. Two large, flat screens TVs are mounted to the wall at either end of the bar and usually feature sports or the news, with the occasional movie. The bar has no air conditioning, so two large fans are mounted on the ceiling where the wall separating the spaces once stood.

Each of these bars has a different feel. Everything from the location and storefront of the bar to the décor and the bartenders themselves operate as a marker for people to understand who is to be in the space. The 
Point's chic industrial atmosphere is a popular theme in post-industrial city bar scenes and its small size offers a more exclusive feel. In comparison, Ray's Place is a huge open space with cathedral ceilings and a forty-six-foot bar to accommodate a large number of patrons at a time. The importance of this is echoed by the owner who boasts of his bar's size, which is "three times the capacity of those Oak Street businesses," in reference to an upscale area in Geneva. Mertin's décor is casual and comfortable, inviting and invoking the sense of community and connection that patrons expressed as important. The atmosphere and décor in each of these spaces sets a tone that serves as a marker for patrons to decipher who frequents the bar, when, and why. This bar wisdom tends to be drawn along class lines in the city of Geneva as patrons understand The Point to be an upscale experience, Ray's Place to be a classic local bar with a blend of a college bar identity, and Mertin's bar to be a traditional working-class bar.

The physical décor and atmosphere of these bars creates and reinforces typical patronage. Through bar wisdom, patrons understand these markers in the décor and atmosphere of the bars that signal that the spaces are meant for high-end, classy consumption; loud college partying; or the casual sociability of a local bar. In moving through these spaces, patrons learn and reproduce information about who uses each of these three types of bars and position themselves accordingly. These understandings of social behavior are often drawn along lines of class. Patrons tend to stick to social types like themselves in these nightlife scenes, utilizing bar wisdom to produce and reproduce integrated segregation in downtown Geneva.

\section{"Brush Your Teeth Before You Come to the Bar"}

Clothing and physical appearance become tools to decide who should and should not be in certain spaces. This was evidenced by the steady commentary from bar owners and bartenders regarding attire and physical appearance as coded language about class and age. John, a bar owner at The Point, commented that people are mostly "dressed up to be out at night" when they go to The Point. He claimed that this was an "important thing" and added that "they're here to be out and be seen...you know...brush your teeth before you come to the bar." In reference to how people dress and present themselves, John emphasized the importance of having what he considers good personal hygiene and appropriate attire and added that, "you don't know who you're going to meet," and that "your professionalism and self-respect comes across and people trust you more." He tells me that "there's an air of...a classic thing...but you get taken more seriously...more respected." John's comments indicate something about the kind of interactions that he expects patrons to have at his bar. The conversation is implicitly about class and a coded understanding of who the bartenders see the space being for. By using coded language about dressing "to be out" and mentioning cleanliness and neatness, John indicates distinctions of who he thinks is to be at The Point and who is not that seem to be drawn along lines of class, occupation, and age. This sentiment is echoed by Pete, a bartender at The Point, when he mentions that "people watch how they dress when they're coming to The Point." He goes on to say if you go into "any townie bar," you will see people "dressed in shorts and a t-shirt at any time," but "if people say, 'hey let's go to The Point tonight,' I think people try to... you know... wear business casual type of dress. They don't just put anything on." Here, Pete compares The Point to "townie bars"-a derogatory term for bars that workingclass Geneva residents visit. The comment makes a class distinction between the bars by referencing how people dress and present themselves in each space. Commentary like this stems from Pete's bar wisdom and serves as boundary enforcement about who nightlife workers think The Point is for.

When the question of attire in the bar came up in my interview with Jimmy, a bartender at Ray's Place, he immediately began talking about the respectability of certain styles of dress, saying, "it's hard to respect people when they dress the way they do," in reference to guys and then added "for girls, they wear dresses that could be a night gown ... these are the girls that get mad when something happens ... it's like, respect yourself." He added that this comment applies mostly to students, but that there were some locals that dressed this way as well. While 
his comment was riddled with victim-blaming and gendered expectations of "respectability" (not to mention infantilizing women by calling them "girls"), it alluded to the importance of style of dress as a component of bar wisdom used to determine who fit in with what groups in which spaces. Students tend to dress in designer clothing from brands like Vineyard Vines, J Crew, and Lilly Pulitzer, whose pastel colors and distinct style contrast sharply with the attire of locals in Geneva. Here, Jimmy commented about the difficulty in respecting this style of dress. The men's attire was not perceived as manly enough and the women's was not seen as respectable. This comment was important not only for its ageism and misogyny, but also in its comparison to the workers' perceptions about the style of dress of other groups in Ray's Place. Since Ray's Place is a contested space in struggles over its identity as a local bar and as a college bar, it is one of the only places where groups with distinct styles of dress came together regularly. Local patrons discussed style of dress as a form of othering between themselves and students. Overall, the college students' attire was more preppy party clothing, while locals tended to dress more casually. On nights when locals and students were both in the space, it became clear that people differentiated themselves by style of dress and appearance.

In Mertin's bar, almost everyone was in casual clothing. Often patrons came in wearing their work clothes with paint on their pants or grease on their shirts. Almost everyone wore blue jeans and some type of sweatshirt. Mertin's also had a group of regulars who were in motorcycle clubs. These patrons often visited the bar wearing their leather jackets and vests that featured the names of their club, their own names, and various other patches. The style of dress in Mertin's was different from the other two bars, particularly because Mertin's patrons were almost all regulars. This became clear to me very early on in my ethnography as I was attempting to manage my identity in each of the bars.

In my formal interviews and informal conversations with patrons, bartenders, and owners, it became clear that attire and overall appearance were markers of bar wisdom used by patrons and bar staff to manage themselves in the bars as well as evaluate others in the space. These conversations and judgements explicitly discussed physical clothing and appearance that served as indicators of how different nightlife participants decided who was supposed to be in what spaces - often drawn along lines of class and age. Patrons of these spaces would visually evaluate one another based on these markers of clothing and physical appearance to reinforce stratification in the bars and the broader nightlife scene of Geneva. These implicit class, age, and gender rules are negotiated in these conversations about clothing and appearance and aid in the creation of bar wisdom.

\section{"We Can't Go There Yet, It's Too Early"}

Time was another marker of bar wisdom for maintaining integrated segregation in downtown Geneva. Patrons of downtown had a keen understanding of who was to be in what bars at what time. This implicit understanding operated to keep certain groups from certain spaces at all times and also to manage how disparate groups moved through contested space at different times. When Mertin's bar would come up in conversation at both The Point and Ray's Place, many patrons did not even know what Mertin's was. Those that did often dismissed the bar as a space where people are "drinking at all hours of the day ... 10AM people are drinking," as indicated by one young female patron at The Point. A middleaged white male patron at Ray's Place echoes this, laughing when I mention spending time in the bar, and saying, "Why would you go there? It's a bunch of old guys drinking at all hours of the day." Both comments reflect a stereotype about age and class as a component of bar wisdom expressed by nightlife participants about Mertin's attracting "the local drunks" to "drink all day." Both patrons distance themselves from the space and distinguish the bar they visit from Mertin's. This indicates that time becomes a way that patrons of The Point understand acceptable and unacceptable drinking habits and serves as a marker to distinguish Mertin's as a space that people would not visit.

Time was used in other ways to understand the function and identity of bars in downtown 
Geneva. One night at The Point, a group of four young, white folks sitting behind me discussed another bar in Geneva that is known as a classic dive bar. One man in the group suggested heading over to that bar and a woman responded, saying, "We can't go there yet ... it's too early and we'll be kicked out for being overdressed." The group laughed in agreement. Again, markers of attire were present in the woman's comment that they would be "kicked out for being overdressed," but we also see the importance of time in her comment. Her bar wisdom allowed her to understand The Point to be a space for a sophisticated, casual drinking at the beginning of the night and the local dive bar as a place to finish the night with rowdy, cheap alcohol consumption.

Time is also used to mark when bars shift identity. At Ray's Place, for instance, local patrons and bartenders know that on Thursday nights around $11 \mathrm{pm}$, the bar's identity will shift over to a college scene where the tensions based on class and age are felt in the space. As the DJ for the Thursday night crowd moves in to set up and have a few beers around 9pm before the Thursday night rush, conversations and jokes of the "invasion" emerge amongst locals and bartenders. Many locals openly voice that they choose to leave the space before students arrive, while others indicate that they stay as an act of defiance against the bar's identity shift towards college students.

In this sense, time becomes another organizing marker of bar wisdom for people to understand and communicate who belongs where. Conversations about time usually employ other markers such as social class, style of dress, age, and drinking patterns. Here we can begin to see how the multiple markers that make up bar wisdom combine to create an understanding of how disparate groups move through the downtown space.

\section{Function of the Bars}

Along with markers of atmosphere, attire, and time, the three bars in the study have different functions that attract and retain certain crowds. Ocejo explains how bars are places for "relaxation, socializing, and fun" and that "As fixtures in neighborhoods, they are repositories of local memory and sources of identity. A bar that is old enough has walls that can tell the history of its surrounding neighborhoods and the people who live there" (Ocejo 2014, 1). Along with being spaces for socializing, bars can be a prism through which to view and understand neighborhood change. This is represented in Ocejo's discussion of the nostalgia narrative of early gentrifiers in New York City, for whom bars became one of the spaces in which the creativity, artistry, and community they treasure were formed. This gave early gentrifiers, "a place attachment based on personal experiences, relationships, and social networks" (Ocejo 2014, 91). The nostalgia narrative these groups created represented an important attachment to the "collective memory, or a powerful social construction of the past in the present" that served to construct new identities and ideologies as symbolic owners that formed the basis for collective action (Ocejo 2014, 92). Grazian notes that blues bars have different functions for different constituents. They are places to consume authentic blues for nightlife revelers and tourists, they are havens for the regulars, and they are places for artistic expression for the people who call themselves blues artists. For May (2014), bars became spaces for fun that nightlife revelers sought. In the studies by Ocejo, May, and Grazian, the functions of bars themselves impacted the ways in which disparate groups understood the space. Oftentimes, conflicts over beliefs about the function of particular spaces caused tensions between groups laying claim to the space. The upscaling of the downtown nightlife scene in Geneva brought about a shift in the function of bars downtown that often clashed with bars' traditional function.

On a casual night at Ray's Place, earlier in the evening, the bartender plays music by Usher and a number of people get excited. The bouncers join in, dancing with a few groups of local patrons and the bartender lip syncs to Usher's words. They all laugh and joke that "it's about to get hot in here." They decide that tonight they are going to play R\&B classics. This important moment represented the personality and social fabric of this bar through its spontaneity and playfulness. After a few minutes of laughing and dancing, Jimmy (the bartender) turns to me and says, "see this is 
what's cool about bars like this." Jimmy's reference to the lighthearted and playful interaction highlights the function of Ray's Place as he understands it. Bar wisdom informs Jimmy's valuation of what bars are supposed to be about and why this bar is special to him. Later in an interview, Jimmy comments that he believes that people enjoy this bar because it is a "meeting ground," adding that "you know you'll see someone you know ... it may not be someone you want to see, but you'll see people you know." He explains that he has seen people get into arguments in the bar or just outside the bar and then settle their conflict over a drink minutes later in the bar. Jimmy's bar wisdom about Ray's Place reflected sentiments of many local patrons who see the bar as part of their lives and identities in their communities. They were referring to ideas about the traditional local bar where "everyone knows your name."

However, students' relationship to Ray's Place is different. They explain that they come every Thursday because "it's where you go on Thursdays" and "the DJ is great." They lament that there are typically only two bartenders working in the crowded bar on Thursday nights and express frustration in trying to get a drink. Based on students' bar wisdom, Ray's Place has a completely different function than it does for local patrons: it is about cheap drinks, loud music, and dancing. These two groups come into conflict with one another, given that their intentions for the function of the bar contrast. Locals prefer to have a few drinks among friends with live music or R\&B classics, while students are looking for fast, cheap drinks and a great DJ. This juxtaposition becomes the most poignant on Thursday nights where the two groups fight over use of the space. This is also one of the clearest moments in which May's concept of integrated segregation is visible.

On Thursday evenings, the bar became spatially divided. Students dominated the center of the bar, conversing and dancing, while local patrons were restricted to the periphery at the front and back of the bar. Spaces such as the dance floor could host some intermingling of locals and students, but this rarely happens. The few occasions when students did dance with locals tended to be students mocking locals by enthusiastically dancing with them and then turning to their friends as they all laughed at the encounter. Locals and students cohabited this space every Thursday evening and almost exclusively ignored one another. By about 11:30 pm, when this Thursday crowd of students packed into the bar, the entire fortysix-foot bar was full of people, locals, and students alike, trying to get drinks. Locals and students stand shoulder to shoulder at the bar and all but ignore one another. There were typically two bartenders working the whole bar, and thus, they were constantly on the move, largely unable to keep up with the sheer volume of requests for drinks that came pouring in. There was an understanding, discussed amongst locals and bartenders when students were not present, that bartenders would serve locals before attending to students. Early one Thursday evening before the rush of students arrived, Jimmy was discussing this telling me "it's about respect, you know? Like, if you come up to me yelling for a drink when you just walked up to the bar, then I'm not serving you." Students strongly expressed that they were aware of this serving order on Thursday nights. Additionally, on numerous occasions during my ethnography, students would turn to me as they were waiting to be served and roll their eyes or make a comment about how long they had been waiting and how the bartender was deliberately ignoring them to focus on "townies". Bar wisdom informs how the space is understood by the two groups that use it and when these groups cohabit the space, tensions arise about the function of the bar.

In comparison, Mertin's bar is less contested by various performances of the nocturnal self, but rather is the type of bar Ray Oldenburg (1989) would have called a third place. It functions as a space for patrons to come together and bond outside of work, family, and other commitments (Oldenburg 1989). In Ocejo's account of patrons of Milano's, a local Bowery bar in lower Manhattan, "going to the bar is intertwined with their local identities and provides them with a regular opportunity to maintain friendships and strengthen local ties...they do not manufacture and put on a 'nocturnal self' but embrace the freedom the bar gives them to act comfortably, apart from work and family" (Ocejo 2014, 24). This is similar to the function and identity of Mertin's as a 
local bar as exemplified through the bar wisdom of its patrons. The bar was a space that was frequented by the same people all the time. It did not see the transient, nightlife crowd like some of the other bars in Geneva. This was evidenced by the fact that many students had never heard of the bar, let alone been there. Mertin's served no function for students and, thus, was not even on their radar. Additionally, stereotypes regarding class and age prevented even some locals from associating with the bar.

In comparison with both Ray's Place and Mertin's bar, The Point's crowd was predominantly white professionals. Groups of young, almost exclusively white folks frequented the bar. They ranged from college students to young professionals from Geneva and surrounding areas. They dressed in a manner somewhere between professional and party attire. The space felt white, as groups of predominantly white patrons dominated the dynamic in the bar, in part due to their sheer numbers compared to other demographics, but also in ways that the space and atmosphere catered to them. These groups could be seen most often between 10pm and midnight. Most frequently, groups came in for a cocktail or two and then left again. The nature of this bar lent itself not to excessive drinking and loud drunken engagements, but rather to a sophisticated consumption experience evidenced, in part, by the price tag of its cocktails.

On any given night, it was not uncommon for two groups who came to the bar separately to show that they knew one another and converse, at least briefly, in the bar. These interactions, while sometimes a casual hello to a friend, oftentimes looked like professional networking. One Saturday night around midnight, a well-dressed, young, white man walked in with two similarly well-dressed white women. The two women walked immediately over to a group of six young, white patrons sitting in the corner alcove behind where I was seated at the bar. The man approached the bar next to me and upon making eye contact with one of the bartenders, reached over the bar and shook his hand, referring to him by name. The bartender asked how he was doing and they conversed about job openings in the man's real estate firm, the bartender's purchase of a home, and common professional acquaintances. This was an example of how this upscale bar created not only an urban, upscale nightlife experience, but also a professional environment in which casual networking could take place. This bar became mixed-use in blending the line between nightlife space and an environment for professional engagements.

The manifestation of this bar as a crossover between party and professional environment is a product of a number of dimensions of the space working together and patrons' bar wisdom about it. First, the bar was frequented most by an upscale, white, professional crowd. This was evident in the high-priced, elaborate cocktails and the cocktail knowledge of the bartending staff that must accompany these extravagant drinks. Also, the positioning of the bar in the downtown space gave it a central location, as it was situated in the middle of the city, but also a mysterious, exclusive feel in that the exterior of the bar was dark with drapes covering the windows and only a small sign advertising the business to the street front. Everything from the private, exclusive feel of the bar's exterior to the atmosphere inside and the price tag of cocktails, alluded to the space's dual function as an environment for upscale consumption as well as professional networking and interaction. These markers coincided with implicit bar wisdom about the function of different bars in Geneva that guide nightlife revelers through space and helped them to decide which bars to visit and which to avoid.

\section{Researcher in the Space: "Are You a Poet?"}

Navigating my role as a researcher in each of the spaces became an informative way of understanding how bar wisdom and integrated segregation (May 2014) works. As a young, white, female college student, the ways in which I was perceived in the different spaces often reflected preconceived ideas about who ought to be in the respective spaces. I became cognizant of each facet of my identity as I moved through the spaces, attempting to fit in for my research. I would match my dress, hairstyle, and makeup in each of the bars in an attempt to fit the space. For instance, at The 
Point, my positionality as a young, white, woman lent itself to my fitting into this bar fairly easily. I resembled the predominant crowd that frequented this bar and could position myself in demeanor, style of dress, and behavior in a way that did not seem odd. Also, this bar atmosphere itself was convenient as a research setting in that it was dimly lit, with numerous alcoves and spaces for me to sit while still being able to see the bar. Also, the trend of groups sticking to themselves made it a bit easier for me to blend in sitting at the bar alone. I was perceived as somewhat mysterious and was promptly told this and asked by a patron if I was a poet or a writer. The combination of these factors allowed me to position myself discreetly into the space and be perceived with a "Hemingway quality" as a young woman, sitting alone in the bar, with a notebook nearby. While patrons did not often engage with me as a researcher, occasionally, patrons would ask further questions about what I was doing and would discuss how they thought what was happening in Geneva was a positive thing that was bringing economic activity back into the city. They also remained aware of my presence as a researcher, offering up comments like "Write that down!" or "Did you get that?" in reference to part of their conversation or happenings in the bar. I understood this as them informing me what they felt my research was about and what types of things should be included in it. It also served as a way for them to interact with me on a more personal level in the bar. It was much easier to jot down notes in this bar given the nature of interaction in the space. Groups at The Point tended to stick to their own groups. This lack of intermingling allowed me to sit in the bar largely undisturbed, able to write down fieldnotes fairly freely.

My positionality in Ray's Place was more complicated and contested than in The Point. Through the bar wisdom I developed, I found that there was a tension between my role as a student affiliated with an elite, liberal arts college and my presence in the bar alone, seemingly separate from that identity, as students never visited Ray's Place without friends. While it seemed to me that bartenders and local patrons expressed reservations about my presence given my status as a student, most warmed up quite quickly to my presence in the bar upon talking with me. My role as a researcher in this space was complicated. My sitting in the corner of the bar with a notebook did not appear intriguing and mysterious, as it did in the upscale bar, but rather felt out of place. I got a lot of confused looks from local patrons and a few questions as to what I was doing. When I would tell them about my research, they still seemed to be a bit confused, but generally accepted my presence. This negotiation of my identity became more challenging on Thursday evenings, when I would see plenty of students I knew, where the bar wisdom of locals and students conflicted, and my presence seemed peculiar to each group. Many would laugh and ask what I was doing given that my position as a student indicated that I should be behaving like them, rather than sitting in the bar alone with a notebook recording interactions and occurrences. This also complicated the nature of my relationship with local patrons and bartenders, given that they had grown to understand me and developed a relationship with me where my identity as a student had been secondary, but on Thursday evenings, that part of my identity was forced to the forefront because of the demographic shift of the bar.

Negotiating my role in Mertin's bar was quite challenging. My age was a problem because I was decades younger than most of the patrons. In addition, I was often perceived as out of place. One night, one man with whom I spoke throughout the night continued to tell me, "Honey, you're in the wrong bar." He was implying that I did not fit into this space given the combination of my age, social class, and gender. He was leveraging his bar wisdom in making the connection to the other bar scenes in Geneva being the "right bars" for me to be in. My patronage of this bar did not make sense to him. On another night, a middle-aged, Black man approached the bar next to me and ordered a drink. While he was waiting for his drink, he turned to me and asked if my notebook was my diary. This comment implied an understanding of what a woman who looked like me was doing writing in a notebook. There was an assumption, based on my age in comparison to most patrons, that I was writing in my diary-a form of infantilization based on my age and gender. My positionality relative to 
the other patrons did not allow me to be seen as a mysterious writer like I was in The Point. Even after making an effort to adjust my clothing, hair, and makeup to fit into each of the bar scenes, my identity was the most difficult to negotiate in this space. Not only was this a product of how different the intersection of my age, class and gender were from the majority of the patrons, but this also reflected the tight-knit social fabric of this bar that I was interrupting a reality I struggled with as a researcher.

Understanding my identity in each of the bars provided another way of exploring how bar wisdom operates to include and exclude certain people and groups on the basis of certain perceived characteristics and physical appearance. Even when I tried to situate myself in a space to reflect the patrons around me, my identity created complexities that I could not control for and I saw the manifestations of integrated segregation, as well as ways that it could be challenged. While I was always vigilant about how I was being perceived, and my interactions with bar patrons and staff often took time, most of the time, I was able to have meaningful conversations with those outside of my perceived social circle. The complexities of managing my identity in each of these spaces was a testament to the intricacy and complexity of bar wisdom and integrated segregation as they manifested and operated in downtown Geneva.

\section{Conclusion}

I began this project wanting to understand how disparate groups were reacting to and engaging with the upscaling of downtown Geneva and how they navigated their nightlife experience. I used bars as a window through which to understand the intersection of Geneva's culture and commerce. While this development does seem to have diversified the consumption options available in the downtown nightlife scene, it has also altered the character and social fabric of downtown Geneva by catering to the tastes of wealthier and often transient groups. Throughout this article, I have argued that rather than creating an integrated and cohesive nightlife scene in which disparate groups come together in shared space, the current development in Geneva manifests in the fragmentation of the downtown scene in new ways that increase segregation of people in nightlife space. I have laid out the particular mechanisms through which bar wisdom operates downtown and the ways it is leveraged by patrons and bar staff to navigate the nightlife space. This bar wisdom operates to produce and reproduce distinctions between groups in the nightlife and reinforces spatial segregation in the downtown nightlife scene. The production, reproduction, and maintenance of these distinctions in the downtown nightlife manifests in social capsules socializing with those like themselves and exacerbating tensions between groups in the spaces. I also show how conflicts arise over the use of the downtown space and the function of the bars. I have found the bars and the nightlife scene to be a way to explore tensions that develop when cities' commercial growth policies cater to the culture and taste of rootless wealthier consumers at the expense of the working-class people who have roots there. The conflicting stories and beliefs about bar culture and community in downtown Geneva reached far deeper than the voices of the individuals who spoke of them. At the heart of these conflicts over the nightlife culture of a city are questions of place, identity, and belonging. Cities' growth agendas focused on tourism and consumption threaten the culture and needs of working-class residents in the interest of catering to the culture and tastes of wealthy, transient groups. As Ocejo (2014) notes,

What happens when an urban neighborhood of diverse groups becomes increasingly upscale? Neighborhoods open for some but close for others, bars proliferate and thrive but their roots grow weaker, and a place becomes forever transformed. With upscaling comes conflict as well as ephemerality, as anchors of stability lose their strength to ground people amid their turbulent surroundings. (Ocejo 2014, 219)

I think a deeper yearning for democracy in decision making in cities lies at the heart of this contest debate over downtown bar space. Who is Geneva for? Whose needs, culture, and tastes are catered to? What is lost and who is forgotten in this process of commercial upscaling? 


\section{Acknowledgements}

I would like to thank the wonderful people that opened their lives to me, especially the bar staff and local patrons of Mertin's, Ray's Place and The Point. I am grateful for your time, perspective, and honesty, which made this work possible. I would especially like to thank Dr Martha Radice and the editors of the Journal for Undergraduate Ethnography for the opportunity to publish this research. And finally, my deepest thanks to my advisor, Dr Ervin Kosta, for his sharp analysis, perspective, and undying belief in my ability. I could not have done it without you. 


\section{References}

Anderson, Elijah. 1990. Streetwise: Race, Class, and Change in an Urban Community. Chicago, IL: The University of Chicago press.

Grazian, David. 2003. Blue Chicago: The Search for Authenticity in Urban Blues Clubs. Chicago, IL: University of Chicago Press.

Grazian, David. 2008. On the Make: The Hustle of Urban Nightlife. Chicago, IL: University of Chicago Press.

Lefebvre, Henry. 1991. The Production of Space (D. Nicholson-Smith, Trans.). Malden: Blackwell Ltd.

Lloyd, Richard. 2006. Neo-Bohemia: Art and Commerce in the Postindustrial City. New York, NY: Routledge.

Lofland, Lyn H. 1998. The Public Realm: Exploring the City's Quintessential Social Territory. Piscataway, NJ: Transaction.

May, Reuben A. 2014. Urban Nightlife: Entertaining Race, Class, and Culture in Public Space. New Brunswick, NJ: Rutgers University Press.

Ocejo, Richard E. 2014. Upscaling Downtown: From Bowery Saloons to Cocktail Bars in New York City. Princeton: Princeton University Press.

Oldenburg, Ray. 1989. The Great Good Place: Cafés, Coffee Shops, Community Centers, Beauty Parlors, General Stores, Bars, Hangouts, and How They Get You Through the Day. New York, NY: Marlowe.

Zukin, Sharon. 2008. "Consuming Authenticity: From Outposts of Difference to Means of Exclusion." Cultural Studies 22(5): 724748.

Zukin, Sharon, Valerie Trujillo, Peter Frase, Danielle Jackson, Tim Recuber, and Abraham Walker. 2009. "New Retail Capital and Neighborhood Change: Boutiques and Gentrification in New York City." City and Community 8(1): 47-64.

Zukin, Sharon. 2010. Naked City: The Death and Life of Authentic Urban Places. New York, NY: Oxford University Press.

Zukin, Sharon. 2011. "Reconstructing the Authenticity of Place." Theory and Society 40: 161-65. 